\title{
Evolução e Contribuição do Comércio Intraindústria para o Crescimento do Comércio Total entre Brasil e Argentina
}

\author{
Adriana Ferreira Silva ${ }^{1}$ \\ Orlando Monteiro da Silva ${ }^{2}$ \\ Julcemar Bruno Zilli ${ }^{3}$
}

Resumo: O presente trabalho analisa a evolução do Comércio Intraindústria (CII), bem como sua contribuição para o crescimento do fluxo comercial entre o Brasil e Argentina, no período de 1990 a 2007. Para tanto, utilizou-se a metodologia proposta por Menon e Dixon (1997), que decompõe os componentes do comércio nos tipos intra e interindústrias. Os resultados indicaram que, para muitos setores, com a formação do Mercosul, o comércio entre Brasil e Argentina, antes caracterizado por relações comerciais do tipo interindústria, passaram a ser caracterizados por fluxos comerciais do tipo intraindústrias. Entretanto, devido à elevada especialização produtiva entre essas economias, a contribuição dinâmica do comércio intraindústria para o comércio total, mostrou-se, em diversos períodos, inferiores à contribuição do comércio interindústria.

Palavras-chave: Mercosul; Comércio interindústria e intraindústria; Integração comercial.

\footnotetext{
1 Economista, Mestre em Economia Aplicada e doutoranda do Programa de Pós-graduação em Economia Aplicada da Escola Superior de Agricultura "Luiz de Queiroz", pesquisadora do CEPEA/ESALQ/USP, bolsista da Capes, e-mail: adsilva@esalq.usp.br.

2 Engenheiro Agrônomo, PhD. North Carolina State University, Professor Titular da Universidade Federal de Viçosa, e-mail: odasilva@ufv.br.

3 Economista, Mestre em Economia Aplicada, Doutorando do Programa de Pós-graduação em Economia Aplicada da Escola Superior de Agricultura "Luiz de Queiroz", Professor Assistente da Universidade de Passo Fundo, bolsista do CNPq, jbzilli@upf.br.
}

Revista de Economia, v. 36, n. 2 (ano 34), p. 7-24, maio/ago. 2010. Editora UFPR 


\title{
Development and contribution from the intra-industry trade to total growth trade between Brazil and Argentina
}

\begin{abstract}
This study examines the development of Intraindustry Trade (CII) and its contribution to the growth of trade between Brazil and Argentina in the period 1990 to 2007. Thus, the methodology proposed by Menon and Dixon (1997) that decomposes the components of trade types in intra and inter-industry was used. The results indicated that for many sectors, with the formation of Mercosur, the trade between Brazil and Argentina, before characterized by inter-industry trade relations have been characterized by the intra-industry trade. However, because of high production specialization between these economies, the dynamic contribution of trade to total intra-industry trade was in various periods lower than the contribution of inter-industry trades.
\end{abstract}

Key words: Mercosur; Inter and intra-industry trade; trade integration.

JEL: F140, C200

\section{Introdução}

Estudos realizados por Romer e Lucas, na década de 1980, relacionaram o comércio internacional com o crescimento econômico e o desenvolvimento a longo prazo. Tais estudos afirmam que a redução das barreiras comerciais agilizaria o crescimento econômico e o desenvolvimento, na medida em que mudanças tecnológicas endógenas criam externalidades que superam qualquer propensão à obtenção de rendimentos decrescentes (Salvatore 2000).

Um processo de integração econômica entre países em desenvolvimento poderia ser visto como alternativa para viabilizar uma estratégia de desenvolvimento que, segundo Baumann et al. (1998), seria irrealizável na dimensão das pequenas economias periféricas que contam com um mercado doméstico restrito e limitados recursos para ação do Estado.

Ao mesmo tempo, como ressaltado por Krugman e Obstfeld (1999), as nações que se tornam parceiras comerciais vêm se tornando similares em tecnologia e recursos, não havendo, portanto, vantagens comparativas claras dentro de uma indústria. Desta forma, o comércio intraindústria, que se configura em fluxos de bens com intensidades de fatores semelhantes, vem tendo significativo papel no comércio de bens manufaturados entre os países avançados industrialmente, ou seja, as trocas ocorrem em duas vias entre as indústrias 
- provavelmente dirigidas em grande parte pelas economias de escala - em vez da especialização interindústrias conduzida pelas vantagens comparativas.

Para Hidalgo (1993), conhecer de forma mais precisa o comércio intraindústria é de suma importância para a definição da melhor estratégia de política comercial, principalmente num momento em que se esboça, no cenário internacional, um mundo formado por blocos econômicos, em que o fluxo de comércio entre os países é caracterizado por crescente comércio intraindústria.

Em face destes debates, o presente trabalho busca analisar a evolução do comércio intraindústria no fluxo comercial total entre Brasil e Argentina, por capítulos da NCM (Nomenclatura Comum do Mercosul), no período de 1990 a 2007. Paralelamente investiga a contribuição dinâmica do comércio intraindústria no crescimento do comércio entre os dois países.

\section{Metodologia}

\subsection{Procedimentos Metodológicos}

O Comércio Intraindústria (CII) foi inicialmente analisado por Balassa(1966), utilizando uma medida de exportações líquidas $|X-M|$, em valores absolutos, que, quando tomada como uma fração do comércio total $(X+M)$, representaria a proporção do CII de determinada indústria. Grubel (1967), no entanto, alegou que a fórmula proposta por Balassa (1966) indicaria provavelmente mais uma medida de comércio interindústria ou o tipo de comércio proposto pelo teorema de Heckescher-Olhin, do que uma medida de comércio intraindústria.

Nesse cenário surgiu o índice GL de Grubel \& Lloyd (1975), em que aqueles autores assumiram a expressão $|X-M|$ como medida de comércio interindústria e propuseram como medida do comércio intraindústria a diferença entre o comércio total e o comércio interindústria $(X+M)-|X-M|$. Essa diferença tomada como uma proporção do comércio total representaria a participação do CII para dada indústria. O índice de CII do país i com o país j $(j=1, \ldots, \mathrm{m})$, para a indústria $\mathrm{k}(k=1, \ldots, \mathrm{n})$, seria expresso portanto segundo a expressão 01:

$$
\text { (o1) } G L_{i j k}=1-\left\{\frac{\left|X_{i j k}-M_{i j k}\right|}{\left(X_{i j k}+M_{i j k}\right)}\right\}
$$

em que X representa exportações, $M$ representa importações e i, j, e k repre- 
sentam o país de origem, o de destino e o setor da economia, respectivamente. O Quadro 1 resume as explicações associadas a esse índice:

QUADRO 1 - PADRÕES DE COMÉRCIO SEGUNDO A DOTAÇÃO DE FATORES

\begin{tabular}{|l|l|}
\hline $\mathrm{GL}_{\mathrm{ijk}}=1$ & $\begin{array}{l}\text { Todo o comércio é intraindustrial. Logo, os dois países } \\
\text { apresentam idêntica dotação de fatores. O comércio, nesta } \\
\text { indústria, decorre dos efeitos das economias de escala e da } \\
\text { diferenciação de produtos. }\end{array}$ \\
\hline $\mathrm{GL}_{\mathrm{ijk}}=0$ & $\begin{array}{l}\text { Todo o comércio é interindustrial e os países diferem em } \\
\text { suas dotações de fatores e inexistem efeitos das economias } \\
\text { de escala e diferenciação de produtos. }\end{array}$ \\
\hline $0<\mathrm{GL}_{\mathrm{ijk}}<1$ & $\begin{array}{l}\text { A dotação de fatores é distinta e inexistem efeitos das eco- } \\
\text { nomias de escala e diferenciação de produtos, tal que: se } \\
\text { GL } \\
\text { efeitos das economias de escala e da diferenciação de pro- } \\
\text { dutos compensam os efeitos associados com as diferenças } \\
\text { na dotação relativa dos fatores; se GL } \\
\text { comércio interindustrial. Então, os efeitos das economias de } \\
\text { escala e da diferenciação de produtos são compensados pelos } \\
\text { efeitos associados com as diferenças na dotação relativa dos } \\
\text { fatores. }\end{array}$ \\
\hline
\end{tabular}

FONTE: Silva \& Ilha (2004).

Hamilton \& Kniest (1991) argumentam que o índice GL é uma mensuração estática, que captura o CII no período analisado. Entretanto, seria relevante analisar não somente o quanto o CII tem crescido, mas também o quanto desse crescimento tem contribuído para o comércio total. Para aqueles autores, a observação de uma alta proporção do CII em determinado período do tempo não justifica a priori nenhuma provável mudança no fluxo de comércio. Assim, a observação de um aumento no índice GL entre dois períodos de tempo, poderia ocultar uma mudança alta e desigual no fluxo de comércio, condizente com o comércio interindústria (CEI) maior que o ajuste do CII.

Segundo Menon \& Dixon (1997), até mesmo uma simples mudança no índice GL pode ser enganosa se usada para inferir sobre a importância do crescimento do CII. Não se deve, assim, ater-se no crescimento do índice, mas na contribuição dinâmica do comércio inter e intraindústria para o crescimento do comércio total. Sob esta ótica, a forma mais adequada para captar a mudança dinâmica no comércio total do bem $\mathrm{k}\left(\Delta \mathrm{CT}_{\mathrm{k}}\right)$ e as contribuições de cada tipo de comércio seria por meio das seguintes expressões: 
(02) $\Delta C T_{k}=D C I I_{k}+D C E I_{k}$

em que:

(03) $\quad D C I I_{k}=2 \min \left(\Delta X_{k} ; \Delta M_{k}\right)$

(04) $\quad D C E I_{k}=\left|\Delta X_{k}-\Delta M_{k}\right|$

$\Delta \mathrm{Xk}$ e $\Delta \mathrm{Mk}$ representam, respectivamente, as variações dinâmicas nas exportações e importações do produto k. Desta forma, DCII $_{k}$ e DCEI $_{k}$ explicita as variações dinâmicas no CII e CEI, respectivamente. Decompondo as expressões anteriores em medidas percentuais, tem-se:

(05)

$C t_{k}=C d c i i_{k}+C d c e i_{k}$

em que:

(o6) $C d c i i_{k}=100\left(\frac{D C I I_{k}}{C T_{k}}\right)$

(07) $C d e c i_{k}=100\left(\frac{D C E I_{k}}{C T_{k}}\right)$

Quando as exportações e importações se alteram (aumentam ou diminuem) de forma proporcional $\left(\Delta X_{k}=\Delta M_{k}\right)$, os fatores de produção utilizados nas indústrias tendem a se deslocar dentro de indústrias semelhantes, ou pelo menos próximas. Tal fato representa a parcela do crescimento no comércio total $\left(\mathrm{Ct}_{\mathrm{k}}\right)$ composto pela contribuição dinâmica no CII (Cdcii $\left.{ }_{\mathrm{i}}\right)$ e implica menores custos de ajuste dos fatores.

Ao contrário, quando as exportações e importações são modificadas de forma desproporcional $\left(\Delta X_{k} \neq \Delta M_{k}\right)$, por exemplo, um fluxo aumenta e outro não, ou ambos aumentam ou reduzem de forma diferente, gera-se um resíduo de comércio, cujo resultado será a realocação de fatores dentro ou fora de uma mesma indústria $\left(\mathrm{Cdeci}_{\mathrm{k}}\right)$, que poderá levar a mudanças na produção e a 
maiores custos de ajuste dos fatores entre as indústrias.

Em resumo, quanto maior a contribuição do comércio referente à mudança dinâmica no CII ( $\mathrm{Cdcii}_{\mathrm{k}}$ ), (composto pela parcela de mudanças semelhantes nas exportações e importações), menores serão os resíduos e, portanto, menores os custos de ajuste de fatores nas indústrias. De maneira oposta, quanto maior a parcela do crescimento do comércio total representada pela parcela de mudanças "residuais" nas importações/exportações, dados pelo CEI ( Cdeci $_{\mathrm{k}}$ ), maiores serão os custos de ajuste e, portanto, maiores as dificuldades e os entraves no intercâmbio comercial entre os países.

\subsection{Origem e descrição dos dados}

Os dados utilizados dizem respeito aos valores nominais das exportações e importações anuais entre Brasil e Argentina, em milhões de dólares FOB. Os dados dos diversos setores da economia de cada um dos países foram classificados segundo a Nomenclatura Comum do Mercosul (NCM), no período de 1990 a 2007, abrangendo todas as 21 seções (Vide Anexo 1). Paralelamente, formou-se um grupo com as seções entre IV a XVII (exceto as seções V, IX, XIII e XIV), que consideram os setores com produtos manufaturados e semimanufaturados, visando, com isso, uma análise das indústrias que envolvem maior grau de complexidade produtiva.

Todos os dados foram obtidos no site do Ministério do Desenvolvimento, Indústria e Comércio (MDIC 2008).

\section{Resultados e discussão}

\subsection{Evolução do fluxo comercial entre Brasil e Argentina}

A evolução do comércio inter e intraindustrial entre Brasil e Argentina é mostrada na Figura 1. Constata-se que, entre 1990 e 1994, tanto o comércio do tipo interindústria (CEI) quanto do tipo intraindústria (CII) mantiveram tendência de crescimento, com CEI apresentando tendência superior ao comércio intraindústria. A partir de 1995, esse padrão foi revertido, com o CII exibindo valores sempre superiores aos do CEI. Tal resultado sugere que o intercâmbio bilateral entre Brasil e Argentina foi beneficiado pela formação do Mercosul e a redução de barreiras comerciais.

Após anos de crescimento contínuo, os fluxos de comércio inter e intraindústria apresentaram queda em 1999, quando a moeda brasileira apresentou 
significativa desvalorização e a Argentina enfrentou sérios problemas com a recessão. Este impacto foi mais forte no CII, que caiu de um montante de US\$ 9 milhões, em 1998, para US\$ 6 milhões em 1999, contra uma queda no comércio interindústria de US\$ 5 milhões para US\$ 4 milhões.

Após uma pequena recuperação no ano 2000, o fluxo de comércio total entre Brasil e Argentina continuou caindo, voltando a crescer somente a partir de 2003. Esse movimento de expansão do comércio total continuou ao longo do restante do período em análise, com taxas de crescimento sempre superiores para o CII que, em termos de valores, ultrapassou, em 2007, US\$ 14 milhões. Embora em ritmo menos acelerado e em menor volume, o CEI atingiu em 2007, quase US\$ 10 milhões.

FIGURA 1 - FLUXOS DE COMÉRCIO INTER E INTRAINDÚSTRIA ENTRE BRASIL E ARGENTINA (1990-2007)

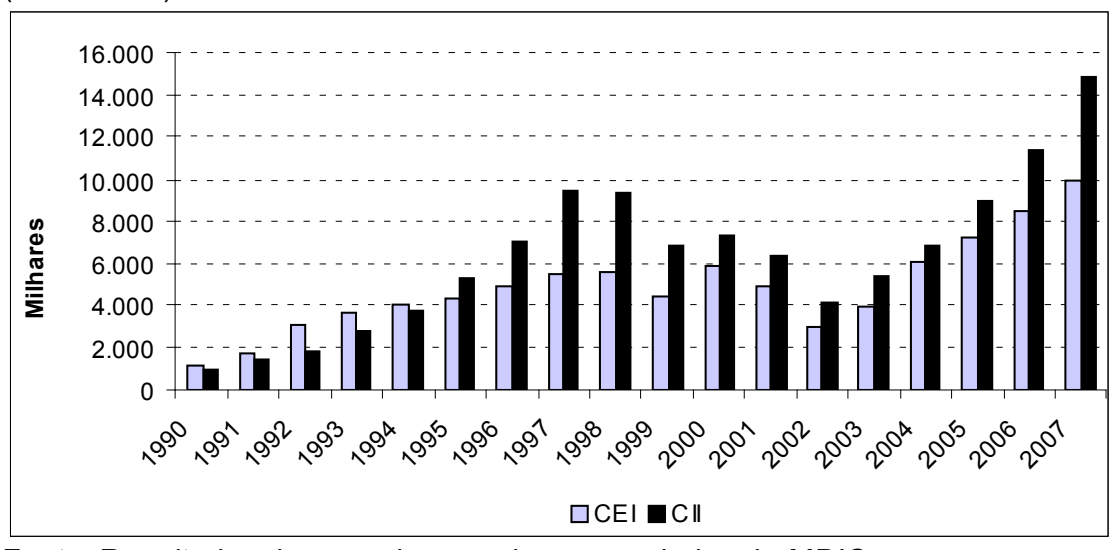

FONTE: Resultados da pesquisa com base nos dados do MDIC

Os valores calculados para o índice GL do comércio entre Brasil e Argentina, são apresentados na Tabela 1.

Os valores do índice variaram entre 0,38 e 0,63 ao longo do período analisado. Até 1994, ano da efetiva formação do Mercosul, o índice manteve-se abaixo de 0,50 , predominando, portanto, um comércio do tipo interindústria entre Brasil e Argentina. Entretanto, a partir de 1995 o índice passou a apresentar maiores valores, que tenderiam a se manter até 1998. No início de 1999, com a desvalorização cambial no Brasil e a recessão da economia argentina desde a segunda metade de 1998, o índice apresentou reduções.

Entre 2000 e 2003 o índice geral manteve-se praticamente estável, variando de 0,56 a 0,58. Em 2004, frente às salvaguardas criadas pela Argentina aos 
produtos brasileiros visando conter a "inundação" de produtos brasileiros naquele mercado, o indicador GL reduziu-se para 0,53 , voltando a crescer a partir daí para atingir praticamente 0,60, em 2007.

\begin{tabular}{|c|c|c|c|c|c|c|c|c|c|c|c|c|c|c|c|c|c|c|}
\hline Seções & 1990 & 1991 & 1992 & 1993 & 1994 & 1995 & 1996 & 1997 & 1998 & 1999 & 2000 & 2001 & 2002 & 2003 & 2004 & 2005 & 2006 & 2007 \\
\hline 1 & 0,03 & 0,18 & 0,69 & 0,97 & 0,50 & 0,22 & 0,37 & 0,44 & 0,53 & 0,44 & 0,49 & 0,71 & 0,22 & 0,69 & 0,60 & 0,46 & 0,40 & $\overline{0,47}$ \\
\hline II & 0,08 & 0,16 & 0,15 & 0,15 & 0,15 & 0,15 & 0,14 & 0,19 & 0,13 & 0,15 & 0,13 & 0,10 & 0,09 & 0,10 & 0,11 & 0,14 & 0,11 & 0,11 \\
\hline III & 0,09 & 0,09 & 0,16 & 0,14 & 0,07 & 0,16 & 0,19 & 0,06 & 0,04 & 0,05 & 0,05 & 0,22 & 0,06 & 0,17 & 0,16 & 0,25 & 0,17 & 0,13 \\
\hline IV & 0,57 & 0,69 & 0,41 & 0,29 & 0,49 & 0,99 & 0,97 & 0,98 & 0,85 & 0,96 & 0,74 & 0,66 & 0,87 & 0,90 & 0,88 & 0,83 & 0,81 & 0,93 \\
\hline V & 0,38 & 0,66 & 0,98 & 0,52 & 0,49 & 0,33 & 0,26 & 0,25 & 0,40 & 0,32 & 0,23 & 0,34 & 0,29 & 0,33 & 0,37 & 0,64 & 0,68 & 0,70 \\
\hline VI & 0,91 & 0,87 & 0,68 & 0,54 & 0,58 & 0,59 & 0,69 & 0,69 & 0,72 & 0,81 & 0,81 & 0,85 & 0,85 & 0,81 & 0,83 & 0,82 & 0,82 & 0,75 \\
\hline VII & 0,96 & 0,53 & 0,44 & 0,39 & 0,50 & 0,74 & 0,76 & 0,65 & 0,74 & 0,73 & 0,80 & 0,97 & 0,79 & 0,93 & 0,95 & 0,95 & 0,89 & 0,80 \\
\hline VIII & 0,01 & 0,02 & 0,04 & 0,04 & 0,04 & 0,04 & 0,09 & 0,06 & 0,11 & 0,16 & 0,18 & 0,19 & 0,24 & 0,18 & 0,20 & 0,23 & 0,36 & 0,22 \\
\hline IX & 0,34 & 0,44 & 0,05 & 0,05 & 0,10 & 0,72 & 0,89 & 0,98 & 0,70 & 0,54 & 0,76 & 0,68 & 0,51 & 0,47 & 0,86 & 0,72 & 0,66 & 0,75 \\
\hline$x$ & 0,57 & 0,38 & 0,15 & 0,09 & 0,17 & 0,61 & 0,60 & 0,64 & 0,70 & 0,58 & 0,67 & 0,54 & 0,84 & 0,63 & 0,55 & 0,53 & 0,61 & 0,61 \\
\hline$X I$ & 0,38 & 0,89 & 0,60 & 0,68 & 0,95 & 0,75 & 0,80 & 0,87 & 1,00 & 0,98 & 0,78 & 0,73 & 0,99 & 0,42 & 0,50 & 0,47 & 0,45 & 0,46 \\
\hline XII & 0,00 & 0,82 & 0,05 & 0,16 & 0,37 & 0,65 & 0,82 & 0,95 & 0,63 & 0,19 & 0,01 & 0,02 & 0,08 & 0,02 & 0,01 & 0,01 & 0,01 & 0,02 \\
\hline XIII & 0,56 & 0,65 & 0,38 & 0,32 & 0,41 & 0,70 & 0,48 & 0,50 & 0,42 & 0,25 & 0,18 & 0,22 & 0,40 & 0,23 & 0,25 & 0,21 & 0,19 & 0,20 \\
\hline XIV & 0,00 & 0,01 & 0,01 & 0,03 & 0,18 & 0,57 & 0,46 & 0,35 & 0,09 & 0,36 & 0,06 & 0,01 & 0,30 & 0,15 & 0,19 & 0,17 & 0,24 & 0,73 \\
\hline$x V$ & 0,00 & 0,37 & 0,13 & 0,18 & 0,15 & 0,29 & 0,34 & 0,34 & 0,40 & 0,43 & 0,42 & 0,50 & 0,88 & 0,64 & 0,38 & 0,39 & 0,36 & 0,36 \\
\hline XVI & 0,95 & 0,69 & 0,42 & 0,42 & 0,46 & 0,76 & 0,61 & 0,67 & 0,60 & 0,57 & 0,48 & 0,59 & 1,00 & 0,53 & 0,38 & 0,31 & 0,29 & 0,29 \\
\hline XVII & 0,95 & 0,59 & 0,40 & 0,69 & 0,80 & 0,86 & 0,96 & 0,91 & 0,87 & 0,95 & 0,93 & 0,69 & 0,58 & 0,76 & 0,56 & 0,59 & 0,72 & 0,83 \\
\hline XVIII & 0,00 & 0,99 & 0,41 & 0,33 & 0,24 & 0,45 & 0,52 & 0,41 & 0,47 & 0,50 & 0,85 & 1,00 & 0,88 & 0,96 & 0,99 & 0,88 & 0,75 & 0,74 \\
\hline XIX & 0,00 & 0,00 & 0,00 & 0,12 & 0,60 & 0,46 & 0,48 & 0,29 & 0,19 & 0,15 & 0,11 & 0,12 & 0,17 & 0,09 & 0,12 & 0,14 & 0,15 & 0,27 \\
\hline$x x$ & 0,64 & 0,66 & 0,11 & 0,11 & 0,17 & 0,76 & 0,75 & 0,65 & 0,63 & 0,28 & 0,18 & 0,16 & 0,54 & 0,29 & 0,15 & 0,15 & 0,12 & 0,12 \\
\hline$X X I$ & 0,25 & 0,00 & 0,96 & 0,00 & 0,96 & 0,71 & 0,44 & 0,07 & 0,06 & 0,02 & 0,01 & 0,00 & 0,00 & 0,00 & 0,00 & 0,02 & 0,01 & 0,06 \\
\hline TOTAL & 0,44 & 0,47 & 0,38 & 0,43 & 0,48 & 0,55 & 0,59 & 0,63 & 0,63 & 0,61 & 0,56 & 0,56 & 0,58 & 0,58 & 0,53 & 0,56 & 0,57 & 0,60 \\
\hline seções* & 0,75 & 0,61 & 0,39 & 0,48 & 0,57 & 0,71 & 0,76 & 0,77 & 0,76 & 0,76 & 0,71 & 0,68 & 0,79 & 0,71 & 0,61 & 0,59 & 0,61 & 0,65 \\
\hline
\end{tabular}

FONTE: Resultados da pesquisa com base nos dados do MDIC

*Seções selecionadas de IV a XVII (exceto as seções V, IX, XIII e XIV), que englobam os setores manufaturados e semimanufaturados. A descrição referente a cada seção é apresentada no Quadro 5 do Anexo 1.

Apesar de pequenas quedas após 1998, o aumento no valor do índice GL, desde 1995, foi suficiente para que o comércio total entre Brasil e Argentina passasse a ser caracterizado como do tipo intraindústria.

Analisando as seções de forma desagregada, verificam-se tendências distintas ao longo do período. Das 21 seções consideradas, somente a seção VI (produtos das indústrias químicas ou conexas) apresentou comércio estritamente do tipo intraindustrial, com índices variando entre 0,54 e 0,91. Após 1998 e com exceção de 2007, os índices encontrados mantiveram valores sempre acima de 0,80. A seção XVII (materiais de transporte) também apresentou índices predominantemente acima de 0,5, com exceção de 1992, quando o índice foi de 0,40 .

De forma contrária, as seções II (produtos do reino vegetal), III (gorduras e óleos animais ou vegetais) e VIII (peles, couros e obras destas matérias) apresentaram índices inferiores a 0,5 ao longo de todo o período, com valores que não ultrapassaram, na grande maioria dos anos, o,20, o que revela, portanto, fluxos comerciais estritamente do tipo interindústria. As seções XIV (pérolas naturais ou cultivadas, pedras preciosas ou semipreciosas e semelhantes) e XIX (armas e munições) também exibiram índices predominantemente abaixo de 0,5, com exceção de um ano em cada caso. Destaca-se o valor observado em 
2007 para a seção XIV, quando o índice GL foi de 0,73, montante totalmente atípico comparado aos outros anos, quando o índice não ultrapassou o,6o.

As seções IX (madeira, carvão vegetal e obras de madeira) e X (pastas de madeira ou de matérias fibrosas celulósicas), que até 1994 exibiram índices inferiores a 0,5, apresentaram valores a partir de 1995 suficientes para que o comércio nessas seções passasse a ser considerado como do tipo intraindústria. A seção XVIII (instrumentos e aparelhos de ótica, fotografia ou cinematografia; instrumentos e aparelhos médico-cirúrgicos, etc.) também passou a apresentar valores maiores para o índice GL a partir do ano 2000 (acima de 0,70), indicando a predominância do comércio intraindustrial.

Já as seções XIII (obras de pedra, gesso e cimento) e XXI (objetos de arte), após grande variação nos valores do índice GL, no início do período, apresentaram a partir de 1995, tendência decrescente, o que as caracteriza como de comércio do tipo interindústria.

Para o grupo de "seções selecionadas", dos setores manufaturados e semimanufaturados, verificou-se que, após um início indefinido no padrão de comércio, entre 1990 e 1994, o índice GL passou a apresentar tendência estável para os valores, que se mantiveram na maioria dos anos acima de o,60. As demais seções (I, VII, XII, XV, XVI, e XX) mostraram oscilações no índice ao longo de todo o período, não permitindo caracterizá-las, portanto, em nenhum padrão específico de comércio.

Contudo, pode-se dizer que o padrão de comércio total entre Brasil e Argentina foi predominantemente do tipo intraindustrial, após a formação do Mercosul, em 1994. O número de seções, com o comércio classificado como do tipo intraindústria, manteve-se em torno de nove no final do período, apesar de várias seções apresentarem padrão de comércio indefinido.

Vale ressaltar, ainda, o padrão mostrado na Figura 2, no qual os índices GL, calculados para as seções que agregam atividades industriais mais comple$\mathrm{xas}^{4}$, tendem a apresentar valores maiores do que aqueles calculados para o fluxo de comércio total que envolve todos os setores (manufaturados ou não). Isso ocorre porque o comércio intraindústria baseia-se no comércio de bens minimamente semelhantes entre os países, o que requer diferenciação e, portanto, algum grau de industrialização do produto, que, por sua vez, tende a aumentar quanto mais diferenciado for este.

A acentuada queda no índice para as seções selecionadas após 2003, fez com que o indicador se aproximasse do índice que agrega todos os setores. Tal fato refletiu os diversos acordos de restrição voluntária das exportações brasileiras à Argentina, firmados entre 2004 e 2005. Tais acordos reduziram os volumes exportados de tecidos, calçados, geladeiras e fogões (setores que agregam elevado processo de manufatura) do Brasil ao mercado argentino,

4 As seções selecionadas envolvem as seções IV a XVII (exceto V, IX, XIII e XIV). 
resultando, ao final, na queda do índice para as seções selecionadas.

Os três últimos anos da análise foram marcados por ligeiras elevações no índice de comércio intraindústria. Por um lado, o elevado nível de investimento brasileiro em setores dinâmicos (automóveis, têxteis, calçados, alimentos e energia) da economia Argentina, ao elevar o nível de desenvolvimento tecnológico e assim assemelhar-se ao padrão brasileiro, contribuiu para a evolução positiva do índice GL. Por outro, a evolução desse índice não foi maior devido as restrições de importação para a "linha branca" brasileira (geladeiras e fogões).

FIGURA 2. EVOLUÇÃO DOS ÍNDICES DE COMÉRCIO INTRAINDÚSTRIA ENTRE BRASIL E ARGENTINA (1990-2007)

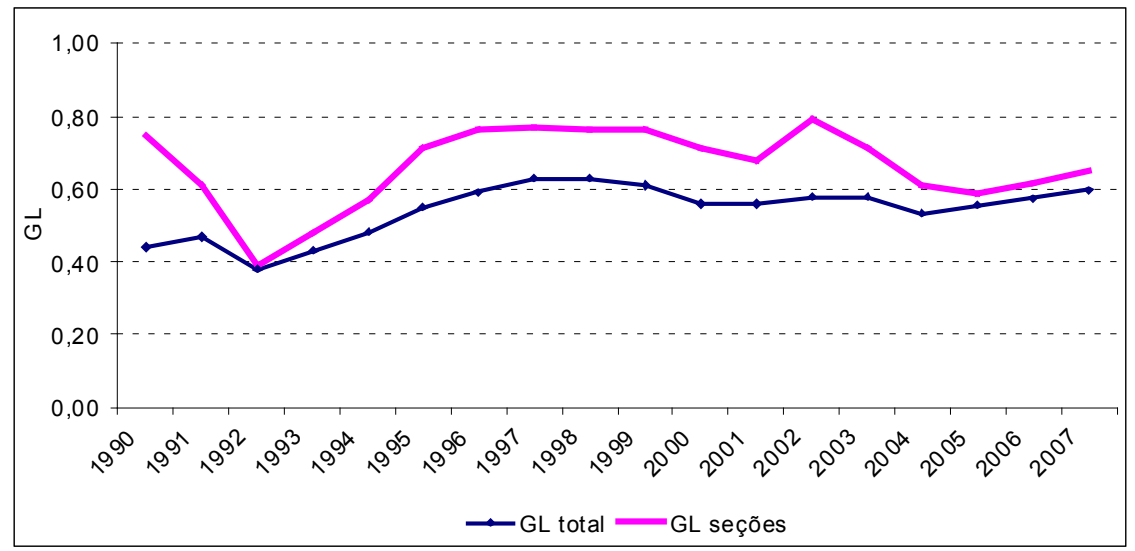

FONTE: Resultados da pesquisa

De forma geral, constatou-se que o Índice GL se manteve, em torno de o,6o a partir de meados da década de 1990, mesmo perante todas as dificuldades políticas e econômicas enfrentadas pelos dois países, predominando, portanto, um volume crescente de comércio do tipo intraindústria. 


\subsection{A Dinâmica dos Fatores de Produção decorrente do Comércio Inter e Intraindústria}

Na seção anterior, a análise do índice GL foi feita de forma estática, com o comércio intraindústria, em dado período, podendo - como descrito por Menon \& Dixon (1997) - apresentar viés, ao não revelar em que proporção este tipo de comércio está contribuindo para a evolução do comércio total. Desta forma, a presente seção aborda a contribuição dinâmica do comércio intra e interindústria para o comércio total entre Brasil e Argentina.

Nos Quadros 2, 3 e 4 apresentam-se os resultados das contribuições do comércio dinâmico inter (Cdeci) e intraindústria (Cdcii) para o comércio total entre as duas principais economias do Mercosul.

No início da década de 1990, Brasil e Argentina passaram por uma série de reformulações de suas políticas externas. No Brasil houve a instituição de uma nova política industrial e de comércio exterior que extinguia grande parte das barreiras não tarifárias. A Argentina, por sua vez, orientou-se na direção de uma aliança com os EUA como forma de garantir recursos financeiros e, ao mesmo tempo, uma maior inserção internacional. Embora pudessem gerar distorções nas relações comerciais entre Brasil e Argentina, estas medidas não impediram que o fluxo de comércio entre os dois países, nos períodos de 1990/91 e 1991/92, apresentasse taxa de crescimento positiva superior a 21\%. A taxa de crescimento do comércio total das seções selecionadas, que envolve os setores de maior complexidade, foi positiva e ainda maior, atingindo, em ambos os períodos, valores superiores a 28\% (Quadro 2).

No período 1990/91, a contribuição dinâmica do comércio intraindústria foi semelhante à verificada para o comércio interindústria. Entretanto, entre 1991/1992 o comércio dinâmico interindústria apresentou uma contribuição de $18,12 \%$ dos $21,23 \%$ registrados pelo comércio total, ou seja, a Cdeci representou em torno de $85 \%$ da taxa de crescimento total do comércio (Cti).

Da mesma forma, a análise desagregada das 21 seções mostrou que neste primeiro período o Cdeci contribuiu de forma mais significava para o crescimento do comércio total entre Brasil e Argentina, situação que se repetiu em 1991/1992. 
QUADRO 2 - CONTRIBUIÇÃO DO COMÉRCIO DINÂMICO INTER E INTRAINDÚSTRIA PARA O COMÉRCIO TOTAL ENTRE BRASIL E ARGENTINA ENTRE 1990/91 E 1995/96 (EM \%)

\begin{tabular}{|c|c|c|c|c|c|c|c|c|c|c|c|c|c|c|c|c|c|c|}
\hline \multirow[t]{2}{*}{ Seções } & \multicolumn{3}{|c|}{$90 / 91$} & \multicolumn{3}{|c|}{$91 / 92$} & \multicolumn{3}{|c|}{$92 / 93$} & \multicolumn{3}{|c|}{$93 / 94$} & \multicolumn{3}{|c|}{$94 / 95$} & \multicolumn{3}{|c|}{$95 / 96$} \\
\hline & Cdcii & Cdeci & Cti & Cdcii & Cdeci & Cti & Cdcii & Cdeci & Cti & Cdcii & Cdeci & $\mathrm{Cti}$ & Cdcii & Cdeci & Cti & Cdcii & Cdeci & Cti \\
\hline- & $-37,8$ & 21,9 & $-15,9$ & $-48,7$ & 54,7 & 6,0 & 6,5 & 10,9 & 17,4 & $-10,8$ & 31,0 & 20,2 & $-5,5$ & 29,2 & 23,8 & $-0,2$ & 4,5 & 4,4 \\
\hline 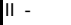 & 4,9 & 5,5 & 10,4 & 0,4 & 5,0 & 5,4 & 1,4 & 8,0 & 9,4 & 1,4 & 5,2 & 6,5 & 2,0 & 11,9 & 13,9 & 0,1 & 4,6 & 4,7 \\
\hline 11 - & 1,9 & 22,0 & 23,9 & $-37,8$ & 19,5 & $-18,3$ & 3,3 & 26,4 & 29,7 & 0,9 & 40,4 & 41,3 & $-14,6$ & 9,4 & $-5,3$ & $-9,9$ & 5,1 & $-4,8$ \\
\hline IV - & $-32,1$ & 36,9 & 4,8 & $-2,7$ & 23,5 & 20,8 & $-2,1$ & 13,1 & 11,0 & 20,8 & 6,0 & 26,7 & $-3,4$ & 20,2 & 16,8 & 4,0 & 2,1 & 6,1 \\
\hline V - & 2,7 & 8,6 & 11,3 & $-4,7$ & 15,9 & 11,2 & 15,4 & 36,2 & 51,6 & 1,9 & 4,7 & 6,6 & $-3,8$ & 13,7 & 9,9 & 1,7 & 16,4 & 18,1 \\
\hline VI - & 5,5 & 3,4 & 8,8 & $-1,4$ & 11,9 & 10,6 & $-1,4$ & 10,6 & 9,3 & 9,4 & 3,7 & 13,1 & 9,9 & 6,2 & 16,1 & 3,5 & 2,9 & 6,4 \\
\hline VII - & 9,2 & 31,5 & 40,7 & 4,5 & 13,8 & 18,3 & 1,8 & 8,6 & 10,4 & 10,5 & 0,5 & 11,0 & 7,2 & 6,4 & 13,6 & 6,6 & 0,8 & 7,4 \\
\hline VIII - & 1,1 & 49,2 & 50,3 & $-13,3$ & 7,2 & $-6,1$ & 0,1 & 0,2 & 0,3 & 0,0 & 3,3 & 3,3 & 0,1 & 4,3 & 4,4 & $-13,0$ & 7,5 & $-5,4$ \\
\hline IX - & $-61,3$ & 61,3 & 0,0 & $-8,4$ & 53,2 & 44,8 & 0,9 & 24,5 & 25,4 & 3,2 & 3,3 & 6,4 & $-25,3$ & 29,0 & 3,7 & 8,1 & 17,4 & 25,5 \\
\hline$x-$ & $-30,2$ & 55,0 & 24,9 & $-7,7$ & 22,2 & 14,5 & $-0,6$ & 20,3 & 19,7 & $-11,8$ & 7,8 & $-4,1$ & 15,8 & 7,4 & 23,2 & 4,0 & 2,7 & 6,7 \\
\hline XI - & 3,4 & 28,6 & 32,0 & 4,9 & 20,6 & 25,5 & 6,5 & 1,0 & 7,5 & 6,1 & 15,7 & 21,8 & 0,3 & 11,7 & 12,0 & 17,5 & 1,8 & 19,2 \\
\hline XII - & 17,0 & 37,0 & 54,0 & $-15,8$ & 67,6 & 51,8 & $-21,0$ & 12,8 & $-8,2$ & 18,4 & 10,4 & 28,7 & 6,8 & 41,8 & 48,6 & 11,0 & 4,1 & 15,1 \\
\hline XIII - & $-15,7$ & 38,6 & 22,9 & $-9,2$ & 17,7 & 8,5 & 4,9 & 16,9 & 21,8 & 4,7 & 0,9 & 5,6 & $-6,4$ & 11,8 & 5,4 & $-7,4$ & 13,5 & 6,1 \\
\hline XIV - & 0,6 & 98,3 & 98,9 & 0,4 & 1,2 & 1,5 & 1,5 & 16,1 & 17,6 & $-191,6$ & 96,2 & $-95,4$ & $-6,3$ & 14,5 & 8,2 & 6,5 & 17,1 & 23,6 \\
\hline XV - & 28,3 & 22,8 & 51,0 & $-3,8$ & 36,4 & 32,7 & $-8,8$ & 5,3 & $-3,5$ & 0,0 & 9,4 & 9,4 & 3,0 & 2,6 & 5,6 & 2,3 & 0,6 & 2,9 \\
\hline XVI - & 3,9 & 21,3 & 25,2 & $-0,6$ & 23,4 & 22,8 & 6,7 & 10,1 & 16,8 & 5,2 & 1,4 & 6,6 & $-4,8$ & 12,0 & 7,2 & $-0,2$ & 10,8 & 10,6 \\
\hline XVII - & 19,8 & 29,6 & 49,4 & 15,4 & 34,5 & 49,9 & 2,2 & 9,1 & 11,3 & 5,9 & 3,4 & 9,3 & $-12,6$ & 16,6 & 4,0 & 15,4 & 3,1 & 18,5 \\
\hline |XVIII - & 0,7 & 33,4 & 34,1 & $-11,5$ & 37,1 & 25,6 & $-2,6$ & 5,5 & 2,9 & $-1,5$ & 13,1 & 11,6 & $-15,0$ & 12,3 & $-2,6$ & 4,9 & 0,7 & 5,6 \\
\hline XIX - & 0,0 & 60,1 & 60,1 & 0,0 & 24,8 & 24,8 & $-25,5$ & 15,4 & $-10,1$ & $-159,0$ & 82,5 & $-76,5$ & 9,0 & 50,8 & 59,8 & 11,8 & 11,1 & 22,8 \\
\hline$x x-$ & 14,3 & 34,6 & 48,9 & $-14,9$ & 46,9 & 32,0 & 2,0 & 17,7 & 19,7 & 4,7 & 9,1 & 13,8 & $-22,9$ & 27,4 & 4,5 & 10,2 & 4,2 & 14,4 \\
\hline XXI - & $-160,0$ & 73,3 & $-86,7$ & 93,8 & 0,0 & 93,8 & $-31,6$ & 66,3 & 34,7 & 27,0 & 26,3 & 53,3 & 5,7 & 19,7 & 25,4 & $-28,8$ & 1,6 & $-27,2$ \\
\hline Total & 11,3 & 10,6 & 21,9 & 3,1 & 18,1 & 21,2 & 10,8 & 3,5 & 14,3 & 6,7 & 2,8 & 9,5 & $-1,1$ & 11,7 & 10,5 & 10,6 & 0,3 & 10,9 \\
\hline Seções & 10,6 & 20,2 & 30,9 & 3,1 & 25,2 & 28,3 & 8,7 & 1,6 & 10,3 & 9,6 & 0,6 & 10,2 & $-0,7$ & 10,2 & 9,5 & 9,0 & 2,8 & 11,8 \\
\hline
\end{tabular}

FONTE: Dados de pesquisa

A queda do presidente Collor e a ascensão de Itamar Franco à presidência brasileira implicou em desaceleração das medidas liberais da política externa, gerando inicialmente maior distanciamento da Argentina e de sua posição seguidora dos Estados Unidos. Entre 1992/93 verificou-se uma queda acentuada no fluxo de comércio total entre Brasil e Argentina, caindo de 21,23\% em 1991/92 para 14,34\% em 1992/93, tendo a contribuição dinâmica do comércio interindústria sofrido a maior retração em relação ao período anterior. Paralelamente, a contribuição do Cdcii de 10,80\% (superior aos 3,11\% observados no período anterior) impediu que uma situação de maior retração fosse verificada nas transações entre os dois países.

Segundo Aveburg (1999) com o Plano Real já em vigor e as políticas de integração comercial do Mercosul em andamento, a condução da política de importações passou a se subordinar aos objetivos da estabilização de preços e proteção (mesmo que moderada) dos setores mais afetados pela recente abertura econômica brasileira. Esses dois interesses passaram a exercer pressões antagônicas, já que o primeiro demandava maior abertura da economia para as importações, enquanto o segundo baseava-se no oposto.

Como resultado, entre 1993/94 e 1996/97 o comércio total entre Brasil e Argentina recuou e estabilizou-se entre 9\% e 11\%. Com exceção de 1994/95 a contribuição dinâmica do comércio intraindústria foi superior a interindústria (Quadro 3). 
Novamente, pôde-se observar valores maiores para o conjunto das seções selecionadas em relação ao total das seções. A exceção ocorreu entre 1994/95, período no qual o comércio dos produtos das seções selecionadas cresceu 9,50\% enquanto o comércio total cresceu 10,51\%.

Os anos de 1997 e 1998 foram marcados por crises. A economia brasileira, assim como diversas economias emergentes, sofreu dois choques seguidos: primeiro com a crise asiática de 1997 e em seguida com a declaração de moratória russa. Perante estes choques as relações comerciais entre Brasil e Argentina ficaram estagnadas e o ano de 1998 foi marcado por um crescimento total de apenas 0,2\% em relação a 1997. A contribuição dinâmica do comércio intraindústria teve uma pequena influência negativa, em paralelo com um ligeiro avanço nas transações dinâmicas interindustriais.

No período entre 1998/99 ocorreu uma forte queda no comércio entre Brasil e Argentina (13,95\%), com o comércio do tipo intraindústria contribuindo significativamente para que tais resultados fossem observados. Tanto para o total das seções, quanto para aquelas selecionadas, houve forte redução no comércio intraindústria, que apresentaram recuo superior a $17 \%$. O comércio do tipo interindústria, por sua vez, registrou taxas modestas, porém positivas, compensando, em parte, o recuo do comércio dinâmico intraindústria.

De acordo com Senhoras \& Vitte (2006), a redução brusca no comércio entre os países a partir de 1998 deveu-se, principalmente, ao retrocesso comercial observado no Mercosul e uma paralisia institucional diante da crise internacional (crise na Rússia em 1998 e uma enorme aversão ao risco dos mercados internacionais) que afetou bruscamente os países da América Latina e o Brasil. Tal fato culminou na desvalorização brasileira que repercutiu nos balanços comerciais e no câmbio dos demais países do bloco, principalmente na Argentina.

Após ligeiro crescimento no comércio dinâmico total no período de 1999/o0, influenciado principalmente pelo comércio do tipo intraindústria, as transações comerciais entre os países voltaram a recuar mais de $8 \%$ no período seguinte. 
QUADRO 3. CONTRIBUIÇÃO DO COMÉRCIO DINÂMICO INTER E INTRAINDÚSTRIA PARA O COMÉRCIO TOTAL ENTRE BRASIL E ARGENTINA ENTRE 1996/97 E 2001/O2 (EM \%).

\begin{tabular}{|c|c|c|c|c|c|c|c|c|c|c|c|c|c|c|c|c|c|c|}
\hline \multirow[t]{2}{*}{ Seções } & \multicolumn{3}{|c|}{$96 / 97$} & \multicolumn{3}{|c|}{$97 / 98$} & \multicolumn{3}{|c|}{$98 / 99$} & \multicolumn{3}{|c|}{$99 / 00$} & \multicolumn{3}{|c|}{$00 / 01$} & \multicolumn{3}{|c|}{$01 / 02$} \\
\hline & Cdcii & Cdeci & $\mathrm{Cti}$ & Cdcii & Cdeci & $\mathrm{Cti}$ & Cdcii & Cdeci & $\mathrm{Cti}$ & Cdcii & Cdeci & Cti & Cdcii & Cdeci & Cti & Cdcii & Cdeci & Cti \\
\hline - & $-3,4$ & 3,5 & 0,1 & $-7,4$ & 5,3 & $-2,1$ & $-6,6$ & 2,2 & $-4,4$ & $-11,3$ & 5,5 & $-5,8$ & $-44,1$ & 20,7 & $-23,4$ & $-29,4$ & 19,0 & $-10,5$ \\
\hline - & $-12,2$ & 6,8 & $-5,4$ & $-0,9$ & 12,3 & 11,4 & $-25,8$ & 12,5 & $-13,3$ & $-0,8$ & 3,2 & 2,3 & $-6,3$ & 2,2 & $-4,1$ & $-22,2$ & 10,4 & $-11,8$ \\
\hline I - & $-0,9$ & 45,8 & 44,9 & $-0,1$ & 12,6 & 12,5 & $-49,2$ & 24,1 & $-25,1$ & $-14,0$ & 6,9 & $-7,1$ & $-120,1$ & 60,3 & $-59,8$ & $-5,4$ & 21,8 & 16,4 \\
\hline 1 - & 9,3 & 0,2 & 9,5 & $-13,3$ & 6,1 & $-7,2$ & $-23,3$ & 10,4 & $-13,0$ & $-4,9$ & 11,9 & 7,0 & $-3,8$ & 4,2 & 0,4 & $-49,3$ & 26,0 & $-23,3$ \\
\hline $1-$ & $-0,8$ & 0,1 & $-0,7$ & $-43,9$ & 22,1 & $-21,8$ & $-4,9$ & 2,2 & $-2,7$ & 5,0 & 28,6 & 33,6 & $-26,6$ & 14,3 & $-12,3$ & $-19,1$ & 6,1 & $-13,0$ \\
\hline $1-$ & 6,9 & 3,1 & 10,0 & 2,0 & 0,5 & 2,5 & $-8,7$ & 5,4 & $-3,4$ & 2,1 & 0,6 & 2,7 & $-4,1$ & 2,5 & $-1,6$ & $-7,6$ & 1,0 & $-6,5$ \\
\hline II - & $-0,8$ & 7,0 & 6,3 & $-6,8$ & 5,0 & $-1,9$ & $-5,5$ & 0,8 & $-4,7$ & 15,1 & 0,1 & 15,2 & $-13,4$ & 11,5 & $-2,0$ & $-16,2$ & 8,2 & $-8,0$ \\
\hline III - & $-1,1$ & 1,8 & 0,7 & $-8,2$ & 5,2 & $-3,0$ & $-0,3$ & 1,6 & 1,3 & 1,3 & 1,9 & 3,2 & 1,2 & 1,5 & 2,6 & $-51,5$ & 24,0 & $-27,5$ \\
\hline K - & 7,1 & 6,2 & 13,3 & $-13,6$ & 14,0 & 0,4 & $-13,6$ & 4,4 & $-9,2$ & $-4,7$ & 9,4 & 4,7 & $-15,7$ & 0,3 & $-15,4$ & $-74,9$ & 37,2 & $-37,7$ \\
\hline- & 5,4 & 0,7 & 6,1 & 4,8 & 1,0 & 5,8 & $-10,7$ & 2,6 & $-8,1$ & 5,2 & 1,7 & 6,9 & $-12,9$ & 2,6 & $-10,3$ & $-54,4$ & 24,4 & $-30,0$ \\
\hline $1-$ & 5,0 & 2,4 & 7,3 & $-14,5$ & 7,0 & $-7,5$ & $-8,4$ & 0,9 & $-7,5$ & $-12,7$ & 9,5 & $-3,2$ & $-9,4$ & 0,0 & $-9,4$ & $-51,2$ & 17,5 & $-33,7$ \\
\hline 11 - & 11,5 & 4,9 & 16,4 & $-23,3$ & 20,2 & $-3,1$ & $-23,3$ & 21,0 & $-2,3$ & $-7,6$ & 18,1 & 10,5 & 0,4 & 1,5 & 1,9 & $-153,1$ & 76,1 & $-77,0$ \\
\hline III - & 6,0 & 3,8 & 9,8 & $-5,3$ & 2,4 & $-2,9$ & $-11,0$ & 4,4 & $-6,6$ & $-3,5$ & 2,9 & $-0,6$ & $-19,0$ & 9,6 & $-9,4$ & $-73,0$ & 35,1 & $-38,0$ \\
\hline SIV - & 0,3 & 14,3 & 14,6 & $-10,9$ & 20,3 & 9,4 & $-35,6$ & 23,3 & $-12,3$ & $-17,9$ & 4,9 & $-13,0$ & $-2,0$ & 18,3 & 16,3 & $-134,8$ & 69,7 & $-65,1$ \\
\hline V - & 4,8 & 9,6 & 14,5 & $-4,5$ & 3,6 & $-0,9$ & $-18,3$ & 7,7 & $-10,6$ & $-0,3$ & 1,3 & 1,0 & $-6,2$ & 5,0 & $-1,2$ & $-54,7$ & 27,4 & $-27,3$ \\
\hline VI - & 12,1 & 2,1 & 14,2 & $-7,2$ & 1,7 & $-5,5$ & $-6,7$ & 1,0 & $-5,7$ & 2,0 & 10,4 & 12,3 & $-27,2$ & 12,4 & $-14,8$ & $-72,7$ & 29,6 & $-43,2$ \\
\hline XVII - & 19,5 & 3,8 & 23,3 & 2,5 & 2,6 & 5,1 & $-37,1$ & 6,6 & $-30,5$ & 1,6 & 1,0 & 2,6 & $-18,1$ & 11,2 & $-6,9$ & $-39,4$ & 6,8 & $-32,6$ \\
\hline VIII - & 0,7 & 12,2 & 12,8 & 7,5 & 2,8 & 10,3 & 4,6 & 2,1 & 6,8 & 0,4 & 13,3 & 13,7 & $-1,8$ & 7,0 & 5,2 & $-33,1$ & 4,5 & $-28,7$ \\
\hline IXX - & $-6,9$ & 14,1 & 7,2 & $-4,6$ & 5,5 & 0,9 & $-16,1$ & 6,2 & $-9,9$ & $-2,1$ & 1,7 & $-0,3$ & $-21,2$ & 10,0 & $-11,2$ & $-61,8$ & 29,9 & $-32,0$ \\
\hline$X X-$ & 3,0 & 8,7 & 11,7 & $-4,8$ & 0,7 & $-4,1$ & $-22,9$ & 11,4 & $-11,6$ & $-1,1$ & 18,1 & 17,1 & $-12,8$ & 5,3 & $-7,5$ & $-126,3$ & 61,4 & $-64,9$ \\
\hline $\mathrm{XXI}-$ & 1,3 & 91,9 & 93,2 & $-40,0$ & 19,1 & $-20,9$ & $-1,5$ & 18,4 & 16,9 & $-0,4$ & 11,2 & 10,8 & $-0,3$ & 5,2 & 4,9 & $-50,0$ & 25,0 & $-25,0$ \\
\hline Total & 10,1 & 0,9 & 11,0 & $-0,2$ & 0,3 & 0,2 & $-17,4$ & 3,4 & $-14,0$ & 7,1 & 0,7 & 7,7 & $-10,1$ & 1,9 & $-8,2$ & $-29,1$ & 6,6 & $-22,5$ \\
\hline Seções & 14,5 & 0,8 & 15,3 & $-0,4$ & 0,9 & 0,6 & $-17,5$ & 1,9 & $-15,6$ & 2,4 & 3,5 & 5,8 & $-14,1$ & 7,4 & $-6,7$ & $-37,2$ & 10,6 & $-26,6$ \\
\hline
\end{tabular}

FONTE: Dados de pesquisa

Em 2001, o governo Argentino resolveu por fim à paridade do peso ao dólar norte americano, instituindo ainda um sistema de câmbio duplo e emitindo quase moedas como meio de troca suplementar. Para Senhoras \& Vitte (2006) a desvalorização cambial brasileira do Real e a posterior desvalorização argentina do Peso agravaram as assimetrias dentro do Mercosul e contribuíram para criar um clima de incerteza nas operações comerciais. Como resultado a queda verificada em 2000/2001 tornou-se ainda maior no período seguinte, ampliadas pelas incertezas provocadas em todos os mercados pelo ataque terrorista nos Estados Unidos. Neste momento, observou-se uma redução superior a $22 \%$, influenciado, principalmente, pela redução de $29 \%$ no comércio dinâmico intraindustrial, uma vez que no comércio interindustrial pôde-se observar uma expansão nas transações. Quando se considera apenas as seções selecionadas nota-se que a redução no comércio total tornou-se mais acentuada, novamente "puxado" pelo comportamento negativo do comércio intraindústria.

Para os cinco últimos anos da análise verificou-se que os dois países estreitaram as relações comerciais, elevando o nível dos bens comercializáveis. Naquele período, o comércio total cresceu, anualmente, sempre acima de 10\% (Quadro 4).

Se entre 2002/03 e 2004/05 o comércio interindústria colaborou de forma 
mais acentuada para que os resultados acima fossem constatados, entre 2005/o6 e 2006/07 o comportamento do comércio dinâmico intraindústria foi fator preponderante no crescimento do comércio total.

Segundo Teruchkin (2004), a partir de 2003, os fluxos comerciais recuperaram-se, principalmente nas exportações brasileiras para a Argentina, que apresentaram crescimento generalizado. A Argentina, por sua vez, perdeu representatividade nas importações brasileiras, levando-a a questionar os benefícios do processo de integração com a adoção de medidas protecionistas unilaterais.

QUADRO 4. CONTRIBUIÇÃO DO COMÉRCIO DINÂMICO INTER E INTRAINDÚSTRIA PARA O COMÉRCIO TOTAL ENTRE BRASIL E ARGENTINA ENTRE 02/03 E 06/07 (EM \%)

\begin{tabular}{|c|c|c|c|c|c|c|c|c|c|c|c|c|c|c|c|}
\hline \multirow[t]{2}{*}{ Seções } & \multicolumn{3}{|c|}{$02 / 03$} & \multicolumn{3}{|c|}{$03 / 04$} & \multicolumn{3}{|c|}{$04 / 05$} & \multicolumn{3}{|c|}{$05 / 06$} & \multicolumn{3}{|c|}{$06 / 07$} \\
\hline & Cdcii & Cdeci & Cti & Cdcii & Cdeci & Cti & Cdcii & Cdeci & Cti & Cdcii & Cdeci & $\mathrm{Cti}$ & Cdcii & Cdeci & Cti \\
\hline 1- & $-42,8$ & 30,3 & $-12,5$ & $-3,5$ & 5,4 & 1,9 & $-2,5$ & 10,7 & 8,3 & 1,4 & 9,0 & 10,3 & 9,0 & 3,1 & 12,0 \\
\hline |11 - & 1,3 & 6,2 & 7,5 & $-6,7$ & 3,3 & $-3,4$ & $-8,8$ & 5,0 & $-3,8$ & 0,2 & 15,2 & 15,4 & 1,7 & 15,1 & 16,8 \\
\hline III - & $-59,9$ & 30,9 & $-29,0$ & 0,1 & 4,6 & 4,7 & $-46,7$ & 23,3 & $-23,4$ & 1,4 & 23,2 & 24,6 & 1,3 & 22,6 & 24,0 \\
\hline IV - & 9,3 & 0,7 & 10,0 & 4,2 & 1,8 & 5,9 & 6,7 & 4,1 & 10,8 & 5,2 & 2,3 & 7,5 & $-0,9$ & 5,6 & 4,7 \\
\hline V - & 0,2 & 1,1 & 1,3 & 6,6 & 6,5 & 13,1 & $-5,0$ & 10,9 & 5,9 & 13,1 & 4,1 & 17,2 & 7,4 & 1,9 & 9,3 \\
\hline V - & 8,3 & 4,1 & 12,4 & 11,9 & 1,3 & 13,2 & 5,6 & 2,1 & 7,7 & 3,9 & 0,9 & 4,8 & 2,3 & 4,6 & 6,9 \\
\hline VI - & 0,9 & 12,8 & 13,7 & 16,3 & 0,3 & 16,6 & 11,7 & 0,4 & 12,1 & $-1,3$ & 3,4 & 2,0 & 3,2 & 5,5 & 8,7 \\
\hline VII - & $-3,2$ & 2,4 & $-0,8$ & 1,3 & 1,7 & 3,0 & $-42,6$ & 19,7 & $-22,9$ & 4,3 & 2,1 & 6,5 & $-6,2$ & 9,8 & 3,6 \\
\hline IX - & 20,5 & 25,3 & 45,8 & $-27,2$ & 21,5 & $-5,8$ & 4,6 & 10,0 & 14,5 & 2,6 & 5,8 & 8,5 & 4,2 & 2,7 & 6,9 \\
\hline X - & $-2,7$ & 12,9 & 10,3 & 3,6 & 9,7 & 13,3 & 3,8 & 4,4 & 8,2 & 9,7 & 0,4 & 10,1 & 7,3 & 4,5 & 11,9 \\
\hline XI - & $-6,8$ & 36,9 & 30,1 & 7,6 & 0,3 & 7,9 & 2,1 & 5,5 & 7,6 & 0,7 & 3,4 & 4,1 & 2,7 & 1,4 & 4,1 \\
\hline XII - & $-0,3$ & 62,1 & 61,8 & $-0,2$ & 18,4 & 18,2 & 0,2 & 3,9 & 4,1 & 0,2 & 4,8 & 5,0 & 0,7 & 14,8 & 15,5 \\
\hline XIII - & $-2,1$ & 21,5 & 19,4 & 5,4 & 14,2 & 19,6 & 0,2 & 8,1 & 8,3 & 1,7 & 11,9 & 13,6 & 2,7 & 9,2 & 11,9 \\
\hline XIV - & 3,0 & 42,1 & 45,1 & 6,9 & 22,3 & 29,3 & 1,3 & 12,0 & 13,3 & 5,8 & 5,9 & 11,7 & 14,8 & 11,0 & 25,8 \\
\hline XV - & $-0,9$ & 16,1 & 15,1 & $-0,5$ & 24,9 & 24,5 & 5,4 & 7,3 & 12,7 & 1,6 & 6,4 & 8,0 & 5,3 & 9,6 & 14,9 \\
\hline XVI - & $-0,2$ & 31,0 & 30,9 & 5,1 & 22,0 & 27,1 & 1,8 & 14,3 & 16,1 & 1,0 & 6,1 & 7,1 & 3,0 & 5,9 & 8,9 \\
\hline XVII - & $-15,4$ & 31,6 & 16,3 & 8,7 & 18,9 & 27,6 & 11,6 & 6,4 & 18,0 & 12,3 & 1,7 & 14,0 & 12,1 & 2,4 & 14,5 \\
\hline XVIII - & $-3,2$ & 7,9 & 4,7 & 14,5 & 1,0 & 15,5 & 1,2 & 6,0 & 7,2 & 2,5 & 8,5 & 11,0 & 6,5 & 2,8 & 9,2 \\
\hline XIX - & 1,3 & 41,2 & 42,6 & $-14,3$ & 7,7 & $-6,6$ & 1,6 & 1,7 & 3,3 & 3,2 & 18,1 & 21,3 & 7,6 & 0,0 & 7,6 \\
\hline XX - & $-1,3$ & 29,1 & 27,8 & $-1,1$ & 28,2 & 27,1 & 2,1 & 9,6 & 11,7 & 0,4 & 15,7 & 16,1 & 1,0 & 4,6 & 5,6 \\
\hline XXI - & $-17,3$ & 8,6 & $-8,7$ & $-37,0$ & 18,5 & $-18,5$ & 1,2 & 17,8 & 19,1 & $-63,2$ & 31,0 & $-32,2$ & $-1,0$ & 1,7 & 0,7 \\
\hline Total & $-0,7$ & 13,9 & 13,3 & 7,8 & 8,8 & 16,6 & 4,7 & 6,4 & 11,2 & 10,1 & 0,0 & 10,1 & 10,5 & 0,7 & 11,3 \\
\hline Seções & $-2,2$ & 20,1 & 17,8 & 8,4 & 12,1 & 20,5 & 7,2 & 6,3 & 13,5 & 6,7 & 1,9 & 8,5 & 8,3 & 2,8 & 11,0 \\
\hline
\end{tabular}

FONTE: Dados de pesquisa

Segundo Menon \& Dixon (1997), é essa desproporcionalidade nas transações comerciais entre os países, que leva aos deslocamentos de fatores entre diferentes indústrias, elevando custos, e resultando em um fator de empecilho e entrave para o comércio entre os parceiros.

Não resta dúvida de que as diversas crises que marcaram o período da análise afetaram significativamente o dinamismo das transações intraindústrias, comprometendo os ganhos do comércio entre o Brasil e Argentina. 


\section{Conclusões}

Os resultados encontrados neste trabalho confirmaram a hipótese de que a formação de blocos econômicos, como o Mercosul, é um fator relevante para o aumento de comércio, especialmente do tipo intraindústria entre os países membros. O acordo de integração entre os países do Mercosul fez com que, no Brasil e na Argentina, muitos setores antes caracterizados por relações comerciais interindustriais passassem a ser caracterizados por relações intraindustriais, em função de um aumento no intercâmbio de produtos de uma mesma indústria.

Vale ressaltar que, por várias vezes, as oscilações nas relações comerciais entre Brasil e Argentina não contaram com a adoção de medidas internas condizentes aos problemas e acabaram representando mais um ponto de conflito do que de soluções. Como consequência surgiu, principalmente na Argentina, um conjunto de setores produtivos com deficiências estruturais e competitivas, "sensíveis" à concorrência externa, que repercutiram negativamente no processo de integração entre os países do Bloco.

Como indicado pela teoria do comércio intraindustrial, as grandes oscilações nos fluxos de exportação e importação acarretaram deslocamentos constantes dos fatores de produção entre diferentes indústrias, resultando em maiores custos de ajuste e, portanto, mais um entrave na expansão do comércio entre os parceiros do Mercosul.

O aumento no valor dos índices de comércio intraindústria em várias seções e também o aumento no número de seções com índices GL acima de o,50 indicaram diferenciações produtivas condizentes ao maior relacionamento intrasetorial multilateral entre Brasil e Argentina.

Uma importante característica do período estudado é a consolidação do Brasil como fornecedor de produtos de maior valor agregado e com viés industrial. Além dos índices exibirem padrão de comércio do tipo intraindustrial, o saldo bilateral do Brasil foi positivo para diversas seções, em vários anos, evidenciando o maior potencial competitivo da indústria brasileira nas seções que envolvem atividades industriais mais complexas.

A forte desaceleração comercial ocorrida principalmente após 1998 foi responsável pelo aumento na disparidade produtiva entre Brasil e Argentina, impondo, muitas vezes, maiores custos de produção e novos padrões de intercâmbio na região, impedindo o fortalecimento e a ampliação das relações internas ao Bloco. Esse resultado difere da hipótese adotada no trabalho de que o comércio intraindústria passaria a ter importância preponderante, contribuindo de forma significativa para a expansão do fluxo de comércio entre Brasil e Argentina.

Considerando que o intercâmbio de produtos semelhantes com mesma qualidade é bom indicador de similaridade industrial e de renda entre os países e que ambos dizem respeito ao esquema de integração regional, pode-se 
concluir que o processo de integração comercial entre Brasil e Argentina é ainda incipiente, e de forma geral tem falhado em gerar maiores ganhos de comércio, como maior oferta e diversificação dos produtos transacionados.

\section{Referências}

AVEBURG, A. (1999). “Abertura e Integração Comercial Brasileira na Década de 90”. URL: < http://www.bndes.gov.br/conhecimento/livro/eco9o_02.pdf>. Acesso em: 21 de janeiro de 2009.

BALASSA, B. (1966). "Tariff Reductions and Trade in Manufactures Among the Industrial Countries." American Economic Review, 56(3): 466-473.

BAUMANN, R.\& CANUTO, O.\& CONÇALVES, R.(1998). Economia Internacional. Teoria e Experiência Brasileira. Rio de Janeiro: Campus, 441p.

CAMPBELL, J.(2000). “Aprender o Passado, Pensar o Futuro”. In CAMPBELL, J. (Org.) O Mercosul entre a Realidade e a Utopia. São Paulo: Relumé Dumará, pp. 11-45.

CORREA, P. G.\& LOES, A.(1994). "Impactos Setoriais do Mercosul sobre a Indústria Brasileira: Uma Análise com Base no Padrão de Comércio”. In Congresso de Economia da ANPEC, Florianópolis - SC, pp. 313-332.

CORREA, L. F. (2003). “O Comércio nos Países do Cone Sul”. URL: http://www. mre.gov.br. Acesso em 23 de setembro de 2003.

GRUBEL H.G. \& JOHNSON H.G. (1967). "Nominal Tariff, Indirect Taxes and Effective Rates of Protection : The Common Market Countries 1959”. Economic Journal, 761-776.

GRUBEL, H. \& LLOYD, P. J.(1975). Intra-Industry Trade. London: Macmillan.

HAMILTON, C. \& KNIEST, P.(1991). “Trade Liberalisation, Structural Adjustment and Intra-Industry Trade: A Note”. Weltwirtschaftliches Archiv, 12.

HIDALGO, A. B.(1993) "Intercâmbio Comercial Brasileiro Intra-indústria: Uma Análise Entre Indústrias e entre países”. Revista Brasileira de Economia, 1(2): 243-264.

KRUGMAN, P. R. \& OBSTFELD, M.(1999) Economia Internacional - Teoria e Política. São Paulo: MAKRON Books. 807p.

LÍRIO, V. S. \& CAMPOS, A. C.(2003). "Do Mercosul a Alca. Impactos sobre as Cadeias do Agronegócio Brasileiro”. Viçosa: UFV. 203p.

MACHADO, J. B. \& RIBEIRO, F. J.(1999) “Mudança Cambial e Questões Estruturais”. Revista Brasileira de Comércio Exterior, 1 (61):18-24.

MENON, J. \& DIXON, P. B (1997). "Intra-industry versus Inter-industry Trade: Relevance for Adjustment Costs". Weltwirtschaftliches Archiv, 133: 164-169.

MINISTÉRIO DO DESENVOLVIMENTO, INDÚSTRIA E COMÉRCIO (MDIC). "Valores das exportações e importações Brasil-Argentina". URL: http://aliceweb. desenvolvimente.gov.br. Acesso em: 25 de setetembro de 2008. 
SALVATORE, D. (2000). Economia Internacional. Rio de Janeiro: LTC, pp. 175-209.

SENHORAS, E. M. \& VITTE, C. C. S.(2006). “Avanços e tropeços do Mercosul: Um debate sobre os quinze anos de Integração Regional”. In XIV Jornadas de Jovens Pesquisadores da AUGM (Associação de Universidades Grupo Montevidéo, Campinas, 2006. CD-ROM. Campinas: Unicamp/Cori, 1, pp. 1-10.

SICA, D.(2004). "Mudança Estrutural, Investimento externo e intercâmbio comercial nas duas Maiores economias do Mercosul”. Revista Brasileira de Comércio Exterior 1 (81): 12-31.

SILVA, M. \& ILHA, A. S.(2004). “Avaliação do Padrão de Comércio Brasil-Argentina no período 1989-2001: Uma Ênfase no Comércio Intra-indústria”. Revista de Integração latino-americano 1 (01): 99 -122.

TERUCHKIN, S. U.(2004). “Comércio Assimétrico com a Argentina”. Carta de Conjuntura 13 (9).

Recebido em: 08 de abril de 2009

Primeira resposta em: 23 de junho de 2009

Aceite em: 21 de julho de 2009

\section{Anexo 1}

\begin{tabular}{|c|c|}
\hline Seções & Descrição \\
\hline SEÇÃO I & animais vivos e produtos do reino animal \\
\hline SEÇÃO II & produtos do reino vegetal \\
\hline SEÇÃO III & gorduras e óleos animais ou vegetais; produtos da sua dissociação; gorduras \\
\hline SEÇÃO IV & produtos das indústrias alimentares; bebidas, líquidos alcoólicos e vinagres; fumo \\
\hline SEÇÃO V & produtos minerais \\
\hline SEÇÃO VI & produtos das indústrias químicas ou das indústrias conexas \\
\hline SEÇÃO VII & plásticos e suas obras; borracha e suas obras \\
\hline SEÇÃO VIII & peles, couros, peleteria (peles com pêlo*) e obras destas matérias; artigos de correeiro \\
\hline SEÇÃO IX & madeira, carvão vegetal e obras de madeira; cortiça e suas obras; obras de espataria ou \\
\hline SEÇÃO X & pastas de madeira ou de matérias fibrosas celulósicas; papel ou cartão de reciclar \\
\hline SEÇÃO XI & matérias têxteis e suas obras \\
\hline SEÇÃO XII & calçados, chapéus e artefatos de uso semelhante, guarda-chuvas, guarda-sóis, bengalas, \\
\hline SEÇÃO XIII & obras de pedra, gesso, cimento, amianto, mica ou de matérias semelhantes; produtos \\
\hline SEÇÃO XIV & pérolas naturais ou cultivadas, pedras preciosas ou semipreciosas e semelhantes, metais \\
\hline SEÇÃO XV & metais comuns e suas obras \\
\hline SEÇÃO XVI & máquinas e aparelhos, material elétrico, e suas partes; aparelhos de gravação ou de \\
\hline SEÇÃO XVII & material de transporte \\
\hline SEÇÃO XVIII & instrumentos e aparelhos de óptica, fotografia ou cinematografia, medida, controle ou \\
\hline SEÇÃO XIX & armas e munições; suas partes e acessórios \\
\hline SEÇÃO XX & mercadorias e produtos diversos \\
\hline SEÇÃO XXI & objetos de arte, de coleção e antigüidades \\
\hline
\end{tabular}

Fonte: MDCI 